\title{
MOBY DICK: LA OBSESIÓN DE LA MUERTE COMO DESTINO MANIFIESTO
}

\author{
"Moby Dick: the obsession of death as a manifested destiny"
}

\section{Óscar Gerardo Alvarado Vega*}

\section{RESUMEN}

Este artículo plantea la obsesión, rayana en locura, que posee al capitán Ahab en un afán de venganza que supone no solo su muerte, sino la de los demás marineros a su cargo. Es así cómo, a partir de lo que representa la búsqueda de la ballena, se van prefigurando acontecimientos que permiten prever el fin de estos en su enfrentamiento con Moby Dick, en lo que claramente constituye un rumbo de muerte carente de fama, de honra y de triunfo

Palabras clave: muerte, obsesión, locura, venganza, tragedia, siniestro.

\begin{abstract}
This article shows the obsession, almost madness presented in Captain Ahab and his eagerness to revenge, in which his death and the death of the marines under his charge have been taken for granted.

The whale's searching represents some events that allows us to predict the end of these confrontations with Moby Dick, which clearly constitutes a course of death without no fame, honor or tribute.

Key Words: death, obsession, madness, revenge, tragedy, sinister.
\end{abstract}

Universidad de Costa Rica. Catedrático, Escuela de Estudios Generales. Costa Rica.

Correo electrónico: oscar.alvaradovega@ucr.ac.cr, oalvarado@gmail.com

Recepción: 28/8/14. Aceptación: 2/3/15. 
Esta novela de Herman Melville se publica en 1851, y en ella hallamos lo que puede constituirse como una gama, un encuentro de discursos en donde la filosofía, el intertexto griego, el discurso religioso, entre otros, van anudando la historia de una búsqueda que ha de conducir, de alguna manera, hacia otro discurso, la tragedia y el destino manifiesto, la muerte como salida y fracaso de Ahab en su intento de venganza.

Ismael, que significa Dios escucha, o Dios ha escuchado, es el personaje principal, precisamente el único que logra evadir la muerte en medio de la obsesión desenfrenada de Ahab. La locura del capitán arrastra hacia la muerte a su tripulación, justamente en lo que representa el desenfreno de este en pos de un objetivo. La locura ciega, y con ello ciega a todos. La venganza es, precisamente, la forma más evidente de locura que manifiesta el viejo capitán.

En esta, una novela de aventuras también, el recorrido que efectúa Ismael es en verdad un viaje existencial, la búsqueda, su propia búsqueda, a diferencia de los demás marineros. $\mathrm{Su}$ deseo es conocer y aprehender el oficio, no precisamente buscar en él lo equivalente al enajenamiento en el cual sucumben los demás, psicológica y físicamente.

En este viaje de aventura, más siniestra que de disfrute, el texto parece asimilar la idea de La Odisea, de Homero, en tanto viaje de aventuras, pero colmado de peligros y de aciagos encuentros.

El texto, pleno de descripciones y detalles, configura el encuentro y desencuentro del muchacho con un mundo que le es desconocido, en donde la ballena está pre figurada como el monstruo, cuando en verdad la monstruosidad está de parte de Ahab y sus hombres, perdidos en una búsqueda sin salida, cuyo objetivo se traza desde lo imposible: el enfrentamiento contra una ballena fantástica, invencible, símbolo a su vez de la fuerza del mar y de la naturaleza, contra los cuales sucumbe el orgullo del ser humano.

Es así cómo cada subtítulo del texto prefigura un contenido que se va anudando con los demás y establecen una linealidad de la novela en la cual el encuentro final con la ballena, contra el cachalote como tal, es el paso último hacia la muerte y el aniquilamiento del gran depredador: el ser humano. No es la locura de la ballena, ni la monstruosidad e incluso majestuosidad de ésta, sino la carencia de lógica en la obsesión del hombre por conquistarla en un afán de venganza destinado a fracasar. Ante ello, Ismael cuestiona la contradicción plena de la vida religiosa, su concepto como tal, y la lectura "cristiana" que efectúan los marineros en su mundo o submundo marino: el valor de la vida, el vivir la aventura, prepararse para la muerte, sin renunciar al valor que implica el estar vivo, pero con el "poder" de matar, de cazar a las ballenas, de arponearlas, capturarlas y extraerles todo lo que de ellas resulte rentable. Es el precio de la vida de otros seres fijados por los marineros, como si estos no tuviesen el derecho a la vida de igual manera. La vida del otro, de lo otro, se negocia, no la del ser humano. Es el concepto del hombre como centro de la vida, del mundo.

Por otra parte, la gran cantidad de acciones, de micro acciones que van tejiendo la novela, se enlazan y constituyen los metadiscursos que van apareciendo, tal como el relacionado con el del púlpito, al inicio de la novela, en donde este remite a la vida marítima, y al acontecer del marinero, del ser humano en la vida del mar, con todas sus vicisitudes, triunfos y fracasos. Las grandes pérdidas, las vidas de los marineros, se convierten apenas en una estadística dentro del proceso, pues otros los han de sustituir, pero la vida del marinero debe continuar en su afán de conquista, específicamente la vida de los hombres que efectúan el oficio de balleneros.

Este discurso religioso, en donde la simbología pone de manifiesto la interrelación mar-tierra desde el espacio del púlpito señalado presenta el valor de la vida en contraste con la permisibilidad de cazar y matar a las ballenas y a otras criaturas. No obstante, el mismo Ahab rompe con este discurso desde el momento de su aparición, pues su meta no es el enriquecimiento, el recogimiento espiritual ni la cacería por sí misma, sino la venganza hacia Moby Dick, debido a que esta en otro momento ha cercenado 
una de sus piernas. El odio hacia esta, por lo tanto, deriva en la pérdida de cualquier otro objetivo existencial en la vida del viejo marinero.

De igual forma, la riqueza del texto nos refiere a los conceptos de libertad y destino que circundan el texto. Libertad en tanto posibilidad de Ismael y de su amigo Queequeg, quienes "eligen" su destino a pesar de las imposiciones a que se ven sujetos, pero destino en tanto el recorrido espacial que hacen deriva en un desplazamiento existencial, sujeto a la muerte física y simbólica que implica viajar al lado de Ahab y la locura que obsesiona y condena a este y a sus marineros. El antagonismo, vida-muerte que se desplaza una y otra vez entre la ballena y Ahab, y que al mismo tiempo des-poseen a ambos en esa estructura que teje la novela y alrededor de la cual se mueven todos los demás, va marcando la pauta del relato ante el eventual cierre de tragedia que marca la novela.

$\mathrm{Si}$ bien el elemento autobiográfico no debe verse como parte esencial de lo que nos interesa, sí debe apuntarse, sin embargo, el hecho de que Melville fue marinero y cazador de ballenas, por lo cual los datos de cacería, destace, características de las ballenas, lugares por los cuales circundan, manera de comportamiento de estas, y otros datos que exigen verdadero conocimiento al respecto, dejan claro el grado de conocimiento de este mundo de mar que el autor posee y que vierte en el texto.

La obra, por su parte, deja ver un profundo aspecto filosófico en la forma en que los personajes enfrentan el mundo y sus dudas, así como en sus enfrentamientos con los demás, con el mar e incluso consigo mismos. De allí se desprende el hecho de que el símbolo del enfrentamiento entre el ser humano y el entorno, se vea matizado por la dificultad de asimilarse a un mundo que se convierte, y a lo cual el mismo marinero contribuye, en hostil y calamitoso, sin dejar de lado el sentido depredador y perverso que justifica sus actos de manera arbitraria en contra de las criaturas del océano y de los cetáceos en particular. No debe olvidarse que, al fin y al cabo, el mar ha de cobrar su precio por medio de la mediación simbólica de la ballena, de Moby Dick, la cual acabará con los marineros. La sobrevivencia de Ismael no es casual, sino parte de lo que representa, en términos de narración en primera persona, el lado testimonial del sobreviviente, como respuesta a sus actos de barbarie. Ismael, el menos bárbaro de todos, sobrevive para dar cuenta de la muerte de los demás, como acto justiciero del mar, y en particular de su símbolo, la ballena blanca, aspecto mortuorio de esta, si se quiere, para relatar la conversión de esta en una especie de cementerio, trasladado al mar, para enterrar a los marineros y al propio Ahab.

Ismael, por ello, reflexiona permanentemente en torno a la vida, al ser, a su propia existencia y en torno a la vida de los hombres de los cuales se halla rodeado, como una forma de intentar explicarse lo que cada uno de ellos guarda en sí:

Hay entre estos hombres, bautizados con nombres de las sagradas escrituras - una de las costumbres de la isla- , casos evidentes de que, en su infancia, se impregnaron con el señorial y dramático tuyo y tú del idioma cuáquero, y de que, por la audacia, la temeridad e ilimitadas aventuras, encadenadas unas a otras, de sus vidas, extrañamente vinculadas con sus recónditas particularidades, no son inferiores, por un millar de rasgos de carácter, a un rey del mar escandinavo o a un poético pagano romano. $\mathrm{Y}$ cuando estas condiciones se unen a un hombre de fuerza grandemente superior, con un cerebro globular y un corazón austero, quien además, por el sosiego y reclusión de muchas largas noches de guardia en las más remotas aguas y bajo constelaciones jamás vistas aquí, en el norte, ha sido llevado a pensar independientemente y $\sin$ prejuicios; cuando, después de recibir todas las impresiones dulces o violentas de la naturaleza, acabadas de salir de su pecho, virgen, generoso y confidencial, y por tanto principalmente, y tan sólo con alguna ayuda de ventajas accidentales, se siente inclinado a aprender un intrépido lenguaje altivamente nervioso, entonces este hombre es único en el censo de toda una nación, una poderosa criatura digna de desfile imponente, hecha para nobles tragedias. Y aún considerándolo desde el punto de vista más dramático, no llegaría ser motivo de detracción con respecto al carácter de ese hombre, el hecho, ingénito, o debido a otras circunstancias, de una cierta morbosidad predominante y semivoluntaria yaciente en el fondo de su naturaleza. Porque todos los hombres trágicamente grandes están formados con cierta 
morbosidad. ¡Oh joven ambición, toda grandeza mortal no es más que una enfermedad! (Melville 2004: 64-65).

La cita anterior deja clara la reflexión en torno a la pequeñez del ser humano, enfrentado contra la vida, contra los medios, contra el mar, en donde los sueños de grandeza no son más que quimera. El marinero deambula en un mundo de mar pleno de una fuerza que termina por ser vencida por el océano, por el símbolo de su fuerza que es la gran ballena blanca, ahogado en su propia frustración.

De igual forma, la recurrencia al discurso religioso, presente no solo en los nombres, en los discursos, en la forma de presentarse ante los demás marineros, refiere también a esta visión de mundo en la cual el hombre sueña, pero se pliega a su fe, a sus creencias, como una forma de aferrarse a la vida, al regreso a la patria, al hogar y a la familia.

Al lado de todo esto, cabe señalar, entonces, que entre las probabilidades de género que establece la novela, como expresión de una moderna tragedia al estilo griego, en donde la fuerza de los dioses, ya no solo mitológicos, sino también cristianos juegan un papel importante, en donde el sino se convierte en marca indeleble de la cual nadie puede evadirse, también juega un papel fundamental el hecho de que el texto deja ver un grado importante en el aspecto aventurero. Si bien no es plena novela de aventuras, sí contiene un alto grado de esta, y hace que la aventura se desarrolle en el mar, no en la tierra. Ismael va en busca de aventuras, aun cuando lo que encuentra en mayor grado es el sufrimiento de compartir un mundo que le resulta poco gratificante y nada prometedor

Es de apuntar que el agua y el mar, ante la cosmovisión del marinero, se convierten en elementos místicos, que seducen, según percibe el propio Ismael cuando está ante estos. Es un universo que se abre ante él, pleno de peligros, pero al mismo tiempo seductor, capaz de colmarlo como tal, y de allí que la contemplación se convierta en signo de respecto que emana de estos hacia el personaje. Aun así, el marinero actúa como depredador y lleva su caos al cosmos de las ballenas, de los demás animales marinos, entre los cuales causa estragos y desolación, debido al salvajismo de sus actos, lo cual contrapone los conceptos de progreso y barbarie y los reinterpreta en tanto asigna la violencia y la muerte al ser humano, y el ansia de vida, pero al mismo tiempo el sufrimiento incorporado a causa del hombre, a las ballenas:

Pero al fin descubrimos que por uno de los inimaginables accidentes de la caza, esta ballena se había enredado con la línea del arpón que remolcaba; además, había huido con la pala de descuartizar clavada en el cuerpo; pero si el extremo atada a esa arma se había enredado en la línea del arpón que le daba vuelta a la cola, la pala se había desprendido de la carne. De modo que, atormentado hasta enloquecerse por el dolor, el monstruo se debatía en el agua, agitando violentamente su flexible cola, y al sacudir a su alrededor la afilada arma, hería y mataba a sus propias camaradas (Melville 2004; 289).

Ahab (cuyo nombre significa el hermano es padre) convierte su ley en imposición, su fuerza está por encima de los demás, no solo en tanto capitán, sino por la obsesión de venganza que lo mueve. Es así como su nombre deviene en uno más, pero con el poder de imponer(se) sin admitir objeción alguna. El padre deviene tirano, y se apropia de la voluntad y la fuerza de los demás para alcanzar su objetivo. Es la locura que lo gobierna a su vez y que lo lleva a través del mar en pos de una batalla contra la ballena blanca.

Es por lo anterior por lo cual el himno de Jonás con(tra) la ballena establece una relación de sinonimia entre el capitán, la ballena y el mundo de los balleneros. Es el contexto religioso, de muerte, de lucha, de condena, de éxito, en donde la referencia Dios es parte fundamental del mundo del pescador. Dios es refugio, es el dador de pruebas, es el que pone a la ballena para exaltar la batalla del hombre. Es el mundo del ballenero y su puesta en práctica antes de iniciar su recorrido.

En ese universo variopinto que describe la novela, las visiones de mundo tiene lugar importante, desde lo religioso, en el encuentro y desencuentro con el otro, en torno al a diversidad de culturas y costumbres, en la forma 
de enfrentar lo (des)conocido, etc. Queequeg lo deja claro en el siguiente pasaje:

\begin{abstract}
Al quitarme la carretilla de las manos, para encargarse de ella, empezó a contarme un cuento gracioso de la primera vez que viera uno de esos aparatos. Ocurrió en Puerto Sag. El patrón de su barco le había prestado una carretilla para que transportase su baúl pesado a una casa de pensión. Para no aparecer como ignorante al respecto -por más que lo era totalmente, puesto que no tenía la menor idea de cómo se manejaba una carretilla-, Queequeg depositó en ella su baúl, lo ató fuertemente y luego se lo echó al hombro, carretilla y todo, y así empezó a caminar por el muelle.
\end{abstract}

-Oh, Queequeg-le dije-, cualquiera diría que podrías ser más perspicaz. ¿No se rió la gente?

Al oír esto me contó otro cuento. Los habitantes de la isla de Rokovoko, según parece, para las fiestas de bodas exprimen el jugo fragante de los cocos dentro de una enorme calabaza manchada, semejante a una ponchera, y esa ponchera constituye siempre el gran ornamento central de la estera de paja trenzada, sobre la cual se desarrolla la fiesta. En cierta ocasión hizo escala en Rokovoko un gran barco mercante, y su capitán -según todos los datos un caballero imponente, pero muy puntilloso, cuando menos para un capitán de barco- fue invitado a la boda de la hermana de Queequeg, preciosa princesita que acababa de doblar el cabo de los diez años. Bueno, cuando todos los invitados estaban reunidos en la casa de bambú de la novia, hizo su entrada el capitán y se ubicó, ya que se le tenía asignado un puesto de honor, , frente a la fuente de bebida y entre el Sumo Sacerdote y su majestad, el rey, padre de Queequeg. Después de la acción de gracias - porque en este pueblo también se da gracias como nosotros, aunque, según me dijo Queequeg, no del mismo modo, pues ellos, , en lugar de inclinar la cabeza, miran hacia arriba, como los patos, al dirigirse al Gran Dispensador de todas las fiestas-, después de la acción de gracias, digo, el Sumo Sacerdote da inicio al banquete con una ceremonia inmemorial en la isla; esto, es, metiendo la punta de sus dedos consagrados dentro de una vasija, antes de que empiece a circular el bendito brebaje. Al verse colocado junto al Sumo Sacerdote, tras de observar la ceremonia, y creyéndose - como capital del barcocon derecho de precedencia sobre un simple rey isleño, especialmente en la casa del rey, el capitán procedió fríamente a lvarse las manos en la olla de la bebida, confundiéndola, es de suponerse, con un gran lavamanos.
-¿Y ahora? -preguntó Queequeg- ¿Qué piensas ahora? ¿No se rió nuestra gente? (Melville 2004: 54)

La novela plantea, por lo tanto, el encuentro y desencuentro no solo entre los hombres y las culturas, sino entre el mar y el ser humano, batallas en las cuales existen más oposiciones que posibilidades reales de acercamiento, fundamentalmente en la segunda.

No obstante, y a pesar de lo anterior, Ismael y Quequeg establecen o construyen una relación de amistad a partir de sus experiencias y conocimiento del mar y de otros grupos sociales. Es uno de los pocos lazos que el texto permite, en tanto la historia detalla fundamentalmente el camino hacia la derrota que permea la historia de cada uno.

El mundo que transitan, y se reduce a la caza de ballenas, fundamentalmente, posibilita en algunos acceder a la idea de que la cacería como tal redime al hombre y que la ballena ocupa un pedestal importante en las vidas de los marineros. De hecho, alguno ha de señalar que un barco ballenero ha de constituir su universidad al mejor estilo de Yale y Harvard.

Por lo tanto, la cacería de ballenas se justifica en términos comerciales gracias a su carne, a su aceite, a su grasa y demás elementos que son extraídos de su cuerpo. No obstante, la marca de Moby Dick responde a una diferencia esencial: su blancura es ya cadavérica como lo hemos señalado anteriormente, lo cual le confiere un aspecto macabro, a la par de su comportamiento voraz, y su tamaño desmesurado. Es la muerte de la marca que lleva consigo, y que aplica al otro, al invasor, en este caso Ahab y los suyos, pero de igual manera a todos aquellos que intentan dar cuenta de ella. De igual forma es también macabro el hecho de que los años han transitado por Ahab y por muchos marineros antes, y la presencia de la ballena blanca ha trascendido el tiempo, lo cual la convierte en una especie de monstruo perenne de cara a estos. Su cuerpo, cubierto de heridas, resiste el paso de los ataques y de los años, y desafía a quien ose enfrentarla. De nuevo, la "maldición" que se desprende de su ser es lo que provoca la muerte y el fracaso en los que osan 
intentar capturarla. La obsesión de Ahab obvia el peligro que ello comporta, y arrastra con él a todos sus marineros. Su barco, desde ese punto de vista, es en realidad un gran ataúd flotante, en sinonimia con el ataúd que se le construye a Quequeg cuando se piensa que ha de morir en altamar.

En ocasiones, el texto manifiesta la presencia de monólogos, largos, extensos en demasía, y otros cortos, lo mismo que la presencia de diversas voces en la narración, lo cual va entretejiendo cada una de las acciones, las reflexiones de los personajes, y su forma de inserción en el mundo. A esto se aúna la presencia de lo psicológico y su relación con el entorno vivido por cada uno de los marineros. Es una correspondencia en la cual la alegría, la locura, la frustración, la derrota, el miedo van sucediendo los estados de ánimo de cada uno de ellos. En medio de ello, la figura de Moby Dick, reencarnación de la monstruosidad ante los ojos de los marineros, deviene elemento que complementa tales sentimientos, pero también pone de manifiesto, indirectamente, la monstruosidad que estos comparten como tales. Es por ello por lo que el texto claramente conjunta la visión del bien y del mal como sentimiento que se encuentran y desencuentran de manera permanente, es decir, el bien y el mal son relativos de acuerdo con la visión o percepción de mundo de los personajes. Así, la monstruosidad o perversión de la ballena le es asignada a esta, construida desde la "racionalidad" de los marineros, pues claramente no es esta quien la asigna para sí misma.

Por otra parte, lo sobrenatural aflora a partir de las supersticiones que confieren cualidades portentosas a la ballena blanca o cachalote:

No es de extrañar, pues, que creciendo el volumen de lo que se iba acumulando incesantemente, gracias al simple tránsito sobre los más salvajes ámbitos acuáticos, los dispersos rumores sobre el cachalote blanco, incorporasen la final toda clase de morbosas indicaciones y sugestiones fatales, semiformadas, sobre agentes sobrenaturales, , y así se llegó, en su tiempo y sazón, a rodear a Moby Dick de nuevas y terroríficas leyendas que ciertamente no provenían de cosa alguna que tuviese apariencia visible. De este modo y al final, produjo tanto pánico, que pocos de los que tuvieron conocimiento de Moby Dick gracias a estos rumores, fueron los que se sintieron dispuestos a afrontar el peligro de la mandíbula (Melville 2004: 141).

Queda comprobado el espacio fantasmagórico conferido al cachalote, en una construcción exacerbada que hace de este un monstruo, provisto de características terroríficas. De nuevo el espíritu supersticioso tiene cabida y se apodera, en el imaginario colectivo, de la mente de los marineros.

El terror, cercano al sentimiento que despierta Frankenstein, la criatura de la novela homónima de Mary B. Shelley, se constituye en sentimiento predominante, conferido desde la noción de los marineros en torno a la inmortalidad de la ballena y a su gigantesca y desproporcionada figura de maldad.

Ante la mirada de estos, la figura de la ballena actúa con una inteligencia que escapa a su condición como tal. Presenta una astucia que rebasa la verosimilitud extra textual, aun cuando dentro de la narración tal característica parezca más que probable. Su presencia, incluso diabólica, constituye el morbo construido en torno a su figura, y la presencia enigmática del propio Ahab viene a complementar esa interrelación que se teje y desteje entre ambos.

La tripulación está compuesta por parias, dirigidos por la mano firme y decidida de Ahab, preso de su locura, en pos de una criatura que se describe infernal, y con el objetivo, igualmente monstruoso, de vengarse y matar a esta, objeto de sus infortunios, sino fatal para él y los demás.

Puede señalarse, sin duda alguna, que dos manifestaciones o géneros literarios tales como la epopeya o épica y la novela de aventuras narran o describen grandes acontecimientos, en los cuales los personajes pueden revestirse de heroicidad la mayor parte de las veces, fundamentalmente en el primero de los casos. Esta novela en particular guarda o reviste algunos elementos que la circundan en relación con estas, pero deriva más bien hacia la tragedia, no hacia el triunfo. Es por ello por lo que el viaje en definitiva es un viaje fallido, no de rescate de heroicidad, sino más bien de confirmación 
de un imposible: el triunfo sobre el monstruo. La tragedia los reviste prácticamente a todos, y es Ismael el sobreviviente único que ha de dar cuenta de lo que representa, como testimonio, la hecatombe de su recorrido. Tal percepción trágica hace que en la novela claramente se vaya leyendo la imposibilidad de escapatoria para los marineros. El mar se convierte en el cementerio en el cual han de acabar, o termina devorados por el gigantesco cetáceo. La ballena, cual engendro descarnado, según la descripción que se desprende del texto, espera, a sabiendas de que es perseguida. No busca la muerte, pero es capaz de darla, de imponerla. Esto termina de confirma su aspecto y conformación grotesca y demoniaca, perversa más claramente.

Cabe resaltar, por otra parte, y a propósito de otra novela, Ensayo sobre la ceguera, de José Saramago, que en tal texto la ceguera blanca es la señal de la monstruosidad que adviene sobre los personajes y los circunda, los reduce, hasta convertirlos en seres casi zoomorfizados. De tal manera, la blancura del a ballena Moby Dick, que se sale de los parámetros de cualquier otra ballena, por tamaño, por ferocidad y por astucia, lo mismo que por tiempo de vida, consolida la paradoja que reviste la blancura, y más bien tal color se convierte en siniestro en ambos textos, una manifestación ominosa que contrasta con el color de Babieca, de Rocinante, de Plata, etc. No debe soslayarse el hecho de que en el cuento de Horacio Quiroga, "El almohadón de pluma", el blanco es también un color siniestro, frío, misterioso, que reviste algo oculto a los personajes y termina por aflorar en contra de estos, tal como le sucede a Alicia, en su casa semejante a un castillo, pero desprovista de afecto, de calor, de vida. Tal como blanco linda justamente con el sepulcro, con la blancura marmórea que envuelve la muerte.

Cada descripción de colores, de miedos, de estados de ánimo, de acciones, de pensamientos, van elaborando una casi pictografía que contribuye a delinear el desarrollo del texto en todos sus matices. La novela, "una pintura" narrada desde ese punto de vista, exalta las pasiones humanas, tanto las más sublimes como las más descarnadas, sin dejar de lado al entorno, como ocurre con el mar y el cielo, con las tormentas y el viaje:

La siempre creciente opacidad de la sombra mate
de las nubes que colgaban sobre el mar, tornaban
más y más discernible el blancor de la danzarina
espuma levantada por la carrera. Los chorros de
vapor no se entremezclaban ya; erraban por todas
partes, a derecha y a izquierda (Melville 2004: 174).

La filosofía, la posición reflexiva que rodea y envuelve la obra, termina por confirmar la locura que representa el viaje cuya obsesión plena no es el conocimiento y el trabajo como tal, sino el afán de una venganza. A ello se unen las ideas prejuiciosas que envuelven la existencia de la ballena, como un ser proveniente del averno, diabólica, siniestra, que carga sobre ella el mal. Las supersticiones de los marineros terminan por alimentar tales ideas y se margen a una figura construida desde el imaginario de los marineros y del propio Ahab.

Los diversos metarrelatos que circundan la novela vienen a complementar la historia de la monstruosidad asignada al a ballena y a su legendaria vida, revestida, dentro del imaginario propio de los marineros, de un carácter siniestro, fantasmal, que solo es desafiado as plenitud por el propio Ahab, dispuesto a morir en su encuentro con aquella.

Tal actitud termina por convertir el ballenero en una especie de hombre salvaje, alejado del resto del mundo, obcecado cuando de su propio mundo se trata:

Un largo exilio del mundo cristiano y la civilización
vuelve inevitablemente al hombre a esa condición
en que Dios lo creó, es decir, a lo que llaman estado
salvaje. El verdadero cazador de ballenas es tal
salvaje como un iroqués. Yo mismo soy un salvaje
que sólo debo obediencia al Rey de los Caníbales y
estoy dispuesto, en cualquier momento a rebelarme
contra él (Melville 2004: 208).

Por lo anterior, se puede explicar, en gran medida, la relación antagónica que se va gestando entre el mar, el ser humano y sus criaturas, en una situación de poder y rechazo que produce lucha y desencuentro. El mundo del marinero se construye desde la perspectiva de un objetivo alrededor del cual se van construyendo. Sacarlos de este espacio 
existencial es prácticamente borrar su esencia como tal, su carácter existencial. La admiración que les produce el terror que guarda el océano en cada una de sus criaturas, de la misma manera que el esplendor que estas mismas guardan, hace que el cazador de ballenas construya para sí una cierta espiritualidad contemplativa que la inmensidad y el desconocimiento y reconocimiento del propio mar le ofrece. De allí que el mar para este sea misterio, vida, muerte y seducción, todo al mismo tiempo.

Por lo tanto, el paralelismo existente en la dicotomía vida (sobrevivencia)/muerte entre los marineros y Moby Dick. No hay "diálogo" posible. Desde tal perspectiva, el fin se vislumbra como muerte, como salida inevitable para alguno de los dos. De allí nuestro planteamiento que, más que una obviedad o una redundancia, es un indicador de lucha entre la construcción de un sujeto que se hace como poseedor del poder, del discurso y de la (sin) razón, en contraposición con la (sin)razón del mar, de la ballena, del mundo marino en general, de los desposeídos.

Por ello, las paradojas de la civilización y la cultura, en las cuales el ser humano, que detesta el canibalismo, termina por practicarlo. $\mathrm{Su}$ discurso se vuelve contra sí mismo, lo contradice y lo desdice:

Quizá no sea la extrema untuosidad de la ballena el motivo por el cual los hombres de tierra firme abomina de la idea de comerla: eso parece más bien deberse a la observación apuntada anteriormente: es decir, el hecho de que les parece terrible que un hombre coma un animal marino recién muerto. Y además lo coma iluminado por su propio aceite. Sin duda, el primer hombre que mató un buey fue considerado un asesino; quizá lo colgaron; y si lo hubiesen juzgado los bueyes por cierto que lo hubieran condenado a muerte; y se lo hubiera merecido, desde luego, como todos los asesinos. Vayan ustedes un sábado por la noche al mercado de carnes y observen la multitud de bípedos vivos que contemplan las largas hileras de cuadrúpedos muertos. Este espectáculo, ¿no es para hacer caer un diente de la mandíbula de un caníbal? ¿Caníbales? ¿Quién no es un caníbal? Te aseguro, lector, que para un fiji que ha puesto un flaco misionero en salmuera dentro de su bodega a fin de tener reservas durante la época de carestía, el Juicio Final será más tolerable que para ti, civilizado y culto glotón que clavas las patas de un ganso al suelo y te regodeas con su hígado hinchado en el paté de foie gras que te comes.

Pero Stubb come ballena iluminado por el aceite del mismo animal, ¿no es cierto? Y eso es como añadir un insulto al daño ya hecho, ¿verdad? Mira el mango de tu cuchillo, mi civilizado y culto glotón que comes esa carne asada..., ¿de qué está hecho ese mango? ¿De qué, sino de los huesos del mismo buey que devoras? ¿Y con qué te escarbas los dientes después de engullirte ese ganso cebado? Con una pluma de la misma ave. ¿Y con qué pluma escribía sus cartas circulares el secretario de la Sociedad para la Supresión de la Crueldad contra los Gansos? Apenas hace un mes o dos que esa sociedad resolvió no utilizar sino las plumas de acero (Melville 2004: 228).

Al lado de todo lo señalado, Ismael intenta "leer", procura "descifrar" la profundidad del cachalote (de Moby Dick en su monstruosidad), pero fracasa. Se da cuenta de que tal vez no se puede interpretar al ser humano o al animal en su fluir por la vida. El leviatán, tal como se le conoce por parte de los marineros a Moby Dick, en tanto monstruo, en tanto ente avasallador, resulta finalmente indescifrable. Alrededor de ella se construyen leyendas, historias fantasmagóricas, monstruosas, aunadas al color blanco, que confiere el aura fantasmal que la reviste, particular, única; símbolo también de la muerte que lleva consigo y que termina por provocar en los demás. Desde tal punto de vista, el cachalote, se convierte en esfinge, pues debe ser descifrada, a pesar de que su poder de muerte la transforma en indescifrable. La esfinge es alteridad porque es desconocida. Lo mismo sucede con Moby Dick, de la cual se dice todo, $\mathrm{y}$ al final en verdad nada o poco se sabe. Es misterio, tal como el mar, insondable. Es por ello que el marinero como tal reflexiona también en su relación con el medio, en su inserción en la grandeza del entorno que lo aplasta, y en su particular pequeñez e insignificancia en lo que representa ese mar, que es un mundo aparte, un universo que le resulta conocido y desconocido al mismo tiempo.

La recurrencia al discurso mitológico, a la historia del ser humano y a la reflexión en torno a la vida, va desarrollando las páginas de 
la novela. La discusión que efectúa el narrador en relación con la presencia de la ballena en las aventuras de Perseo, Hércules da cuenta de uno de los tantos acercamientos que mantiene la novela de Melville con otros géneros literarios: el mitológico. En el apartado "El honor y la gloria en la caza de la ballena", la omnipresencia de esta a lo largo de la historia de la humanidad, la ha puesto siempre en conflicto con el ser humano. $\mathrm{Si}$ bien puede pensarse en un acercamiento en ocasiones, lo cierto es que la lectura insiste en las relaciones de choque, de acercamiento imposible entre el hombre y la ballena, más exactamente entre el ser humano y la naturaleza agreste. La batalla queda en pie de lucha entre ambos. La imposición de uno sobre la otra va delimitando el fin de la novela, la batalla a muerte.

Llama la atención, por otra parte, la paradoja que reviste la recurrencia al discurso religioso, pues los actos mismos de los marineros contradicen el apego a este discurso, pues se aferran a la muerte, a la venganza, al odio, a la blasfemia, lo cual hace que coexistan dos tipos de discursos antagónicos en el diario acontecer de estos, sin que para ellos implique, por sí mismo, una contradicción.

A la par de lo anterior, en esa confluencia de discursos, permanece también el acercamiento del ser humano (el ballenero) y el mar (la ballena/Moby Dick), en una relación de lucha, funesta, lo que lleva, precisamente al hecho de que la tragedia y la destrucción confluyan permanentemente. Tal batalla no es más que la afirmación de la muerte, como lo hemos reiterado. La predestinación alcanza a ambos, pero destruye al ser humano, al ballenero en este caso. La longevidad de la ballena, ya de por sí manifiesta, se extiende hasta lo inverosímil, como una forma de demonizar su presencia a o lo largo del texto. La epopeya en la cual se afirman ambos, que cierra con la lucha final, define la muerte del invasor, y la permanencia, más que justiciera, casi "demoníaca" del leviatán, como se le da en llamar. La batalla entre Ahab y Moby Dick prefigura el final de la novela. Ese último encuentro enajena por completo al capitán, y lo sumerge en la locura plena. Muere presa de su locura y su obsesión.
La inmortalidad de la ballena, de Moby Dick en este caso, pasa por el plano de lo religioso o, incluso, en ocasiones de lo demoníaco, como lo confirma la siguiente cita, extraída, por lo demás, del Libro de Job (42), por parte del autor:

La espada como paja de hierro, y el bronce como leño podrido. La saeta no le hace huir; las piedras de la honda son como paja para él. Tiene toda arma por hojarasca y se burla del blandir de la jabalina (Melville 2004: 266).

El discurso que remite a la Biblia, a los pasajes de esta, viene a conferirle ese carácter entre místico, en ocasiones, mítico en otras, maligno, en no pocas. El encuentro con Hércules, con Jonás, con los profetas, viene a reconfirmar el hecho de que la historia de las ballenas camina junto a la del ser humano, e incluso la precede; es parte del acontecer mismo de la tierra.

La muerte navega al lado de los hombres. En esta novela la simbología camina en cada de las páginas, por lo cual la locura y la muerte, tal como lo contempla el propio Ismael al navegar, le pone de manifiesto el horror en el cual transitan, y la figura fantasmagórica de sus compañeros de viaje, preludio de lo que ha de ser el predestinado final que los va envolviendo paulatinamente:

Esa fue mi sensación cuando tomé la barra del timón y, durante largas horas, guié en silencio la nave de fuego sobre el mar. En ese intervalo, también a mí me envolvió la oscuridad; y gracias a esa oscuridad vi tanto mejor las llamas, la locura, la figura espantosa de los demás hombres. El espectáculo incesante de esas figuras demoníacas que surgían entre el fuego y el humo por fin suscitó en mi alma imágenes equivalentes y pronto cedí al inexplicable letargo que siempre me dominaba durante las guardias nocturnas ante la barra del timón (Melville 2004: 321).

La muerte pasa por el plano de la reflexión filosófica, y del discurso religioso. Hay una necesidad de preparar la salida final, por parte de los balleneros, en su inexorable paso por el mundo. La vida es frágil, y ante tal perspectiva, estos dos discursos se cruzan:

El sol no oculta el océano, que es el lado oscuro de esta tierra y cubre sus dos tercios. Por lo tanto, el mortal que lleva en sí más dicha que dolor, o no es sincero no se ha desarrollado plenamente; y lo 
mismo ocurre con los libros. El hombre más sincero de todos fue el Hombre de los Dolores, y el libro más sincero fue el de Salomón, y el Eclesiastés es el hermoso acero forjado del dolor..."Todo es vanidad". TODO. Este mundo obcecado aún no ha adquirido la sabiduría de Salomón, el no cristiano. Pero el hombre que esquiva los hospitales y las cárceles, y aprieta el paso ante los cementerios, y prefiere hablar de óperas antes que del infierno, al que llama pobres diablos y enfermos a Cowper, Young, Pascal, Rousseau; el que durante su vida despreocupada jura por Rabelais como por el más sabio, es decir, el más alegre, ese hombre no es digno de sentarse sobre las lapidas y romper la tierra verde y húmeda junto con el insondable y maravilloso Salomón.

Pero el propio Salomón dice: "El hombre que se parta del camino de la comprensión permanecerá (aunque esté vivo) en la congregación de los muertos". No te abandones, pues, al fuego. Podrá invertirte, incivilizarte como a mí en esa ocasión. Hay una sabiduría que es dolor, pero hay un dolor que es locura. Y hay en algunas almas un águila de los Catskill que puede hundirse en los más negros desfiladeros para resurgir y desaparecer en las alturas soleadas. Y aunque siempre vuele en los abismos, esos abismos están en las montañas, de modo que aún en sus más hondos descensos, el águila de la montaña está más alta que los pájaros de la llanura, por mucho que ellos suban (Melville 2004: 313).

Acaso en el fondo el ballenero va construyendo la idea de su inminente fin, como una forma de enfrentar sus propios actos de masacre de ballenas; descuartizamiento de estas, mutilación de las mismas, captura, destrucción de estas, lo mismo que exterminio y peligro inminente de extinción a pesar de la longevidad que las caracteriza. La reflexión vital llevada a cabo por Ismael, en su papel de narrador, y por otros marineros, no alcanza para paliar los actos criminales que ejecutan en sus travesías.

El encuentro inminente con Moby Dick perfila la reflexión de cada uno. Quiéranlo o no, la muerte es parte de los pensamientos que albergan los marineros cada día. La añoranza de tiempos mejores, el reencuentro con la familia, el regreso al puerto, la vuelta al mar, y de nuevo la muerte, como preocupación vital. Filosofía, religión, aventura, tragedia, aventura, todo circunda la muerte desde varias perspectivas.
La muerte es la llegada final. Cuando Ahab manifiesta su compromiso total con la muerte de la ballena, en verdad está definiendo no solo su fin, sino el de todos, los cuales guardan terror evidente ante la locura obsesiva de este, sin atreverse a contrariarlo. Ahab reitera su compromiso de vida, su entrega total a su objetivo. Deja claro en sus palabras que solo la muerte ha de detenerlo. Su fin ya está fijado desde ese momento y a partir de tal concepción:

-Estuvo a punto de matarme -murmuró-; sí, este es el mosquete con el que me apuntó: ese con la culata tachonada. Yo quiero tocarlo, sostenerlo. Es raro que yo, después de manejar tantas lanzas mortales, tiemble de ese modo ahora. ¿Está cargado? Quiero verlo. Sí, y con pólvora en la cazoleta. No debería... ¿La tiraré? Un momento, quiero curarme de esto. Sostendré con coraje el mosquete, pensando... Vengo a decirle que hay un viento favorable. Pero, ¿cómo favorable? Favorable a la muerte y al infierno, favorable a Moby Dick. Es un viento que solo es favorable para ese maldito monstruo... ¡Este es el mismo caño con el que me apuntó!... Este, precisamente éste... Ha estado a punto de matarme con el arma que ahora tengo en las manos. Sí, habría estado a punto de matar a toda la tripulación. ¿Acaso no ha dicho que no apocará las velas en ninguna tempestad? ¿Y no ha arrojado su cuadrante? Y en esos mares peligrosos, ¿no busca a tientas su camino, sin más ayuda que su engañosa corredera? Y durante el tifón, ¿no ha jurado que no necesitaba pararrayos? ¿Habrá que aguantar pacientemente que este viejo insensato arrastre al desastre a toda la tripulación de una nave?... En verdad, si a esta nave le ocurriera una desgracia mortal, Ahab sería el culpable de la muerte de treinta o más hombres. Y la desgracia ocurrirá, el alma me lo jura, si Ahab se sale con la suya. De modo que si en este instante lo recluyéramos, no cometeríamos delito alguno. ¿Ah, murmura en sueños! Sí, está allí, precisamente allí, durmiendo... ¿Durmiendo? Sí, pero siempre vivo y listo para despertarse. Cuando estás despierto no puedes soportarte, viejo. No oyes razones, ni protestas, ni súplicas; todo lo desdeñas. Lo único que admites es una estricta obediencia a tus órdenes perentorias. ¡Y después dices que los marineros han dado su palabra! ¡Dices que ya somos Ahab! ¡Dios no lo quiera! Pero, ¿no habrá otro medio?, un medio legal. ¿No podemos hacer de él un prisionero y llevarlo de regreso? Pero cómo... Sólo un loco se atrevería a arrancar la fuerza de las manos de este loco de sus manos vivas. Aunque lo maniataran, aunque lo envolvieran en cables y estachas, aunque lo clavaran al piso de esta cabina, sería más horrible que un tigre prisionero. No se 
podría soportar su vista, no se podría huir de sus aullidos: la paz, el sueño mismo y la inapreciable razón me abandonarían durante el largo e intolerable viaje (Melville 2004: 372).

El miedo se convierte en un sentimiento transmitido y producido en doble vía: ya no es solo el miedo que causa la construcción fantasmagórica de Moby Dick, como la asesina y devoradora, sino que también es el que produce en los marineros la figura también cercana a lo fantasmal del propio Ahab, perdido en su locura y obsesión, con el único objetivo de acometer su venganza, sin importar la vida de los demás, la cual pasa a segundo plano, según sus propósitos. Ante tal perspectiva, cabe replantearse en definitiva de dónde proviene la verdadera monstruosidad, la barbarie que tiene como fundamento una racionalidad que no se sostiene.

Por lo anterior, el mar se convierte en el verdadero cementerio de cada uno de los marineros que viajan con Ahab, con la excepción de Ismael, que logra escapar para "contar" su historia. Esto confirma, precisamente, que la muerte resulta inevitable para estos, que el viaje, es un viaje de muerte, no de caza. La paradoja adviene como la gran ironía, como la misma contradicción que se va construyendo a lo largo del viaje: no se viaja para vivir y sobrevivir, se viaja para encontrar la muerte. Ahab lo tiene claro desde el principio, a pesar de su deseo de venganza. En el fondo sabe que no ha de salir vivo, pero no enfrenta su desatino en soledad, sino que arrastra consigo a toda su tripulación, testigos de la locura de este.

De tal forma, Ahab hace un lado la posibilidad de sentir compasión por los demás, y se refugia en lo único que constituye su centro existencial: la venganza o la muerte, o ambas. El texto mismo define lo que es Ahab: una sombría marcha a lo largo del mar, tras un leviatán que no le permite vivir en paz. Ahab ya no vive. En verdad es un muerto que camina tras la confirmación de su propia muerte, inexorable, inevitable.

Cuando, en uno de los tantos pasajes de la novela, hacia el final de esta, un halcón roba el sombreo de Ahab, en verdad se produce la simbología que remite a la pérdida de lo que ya no se ha de recuperar. La pérdida del sombrero es la pérdida misma de la vida, el fin que se avecina. El encuentro entre Ahab y la ballena blanca ya es la batalla final. La referencia a la muerte y al navegar sobre la propia sepultura que hace uno de los marineros a Ahab, se constituye en el presagio final. Luego, la voz de otro confirma el triste final que les espera:

-¡Ah, miren allí, marineros! -gritó una voz ominosa a nuestra zaga-.Es inútil, extranjeros, que huyan de nuestra triste sepultura: nos han vuelto la espalda sólo para mostrarnos el ataúd (Melville 2004: 389).

El alimento seco y salado del cual se alimenta Ahab en sus cuarenta años como marinero, es el símbolo de la sequedad y la sal que lleva en su alma, como él mismo lo afirma, en otro de los tantos símbolos enunciados en el texto. Su mujer es una viuda con un marido vivo, afirma. De tal forma, el carácter diabólico, pero también sagrado que se asigna a la ballena en su recorrido por el mar al compararla con los prodigios de los dioses griegos, establece con claridad la diferencia entre su aspecto, "revestido" de una superioridad por sobre todas la demás criaturas del mar y la tierra, y la manera en que los hombres se presentan ante esta: temerosos, derrotados, muertos para sí y los demás. De hecho, la boca de la ballena, se abre como una tumba de mármol, según el texto, lo que define el hecho de que la muerte va a recibir a los balleneros.

El encuentro final es el de la astucia de la ballena contra la inoperancia de los marineros. Esta los sobrepasa, los reduce, ataca el barco y lo va demoliendo, mientras los hombres caen al mar, son devorados por esta, se ahogan o mueren en el mismo barco que sufre las embestidas de aquella. Es una lucha desigual. La muerte es el único resultado. Los botes que se lanzan contra esta, para tratar de aniquilarla, poco pueden hacer para enfrentar sus ataques. La aceptación de la derrota por parte de los más cautos, no es la misma de Ahab, inmerso ya en un estado de enajenación del cual no ha de regresar:

-¡Sí! ¡Están hechos pedazos, Stubb! Mira...Pero hasta con un huesos roto, el viejo Ahab está ileso. 
Sólo que este hueso muerto que he perdido era mucho más importante para mí que todos los huesos vivos. Ni la ballena blanca, ni hombre, ni demonio podrá nunca llegar a rozar siquiera al viejo Ahab en su esencia real e inaccesible. ¿Acaso puede una sonda tocar ese fondo o un mástil rasguñar esa techumbre? (Melville 2004: 402).

Las llamadas desesperadas, por parte de Starbuck y otros marineros para que deponga su locura diabólica, se convierte en un intento de alejarlo del camino hacia el infierno, como lo denominan ellos mismos, y de una muerte segura. La derrota no se discute. Estos, con excepción del viejo marinero que los gobierna, ven la batalla contra la ballena como una derrota segura, y una muerte evidente. El apego a lo religioso, como forma de hacerlo recapacitar se convierte en un discurso vacío para aquel.

La descripción que grafica la batalla final de estos contra la ballena reafirma el horror infernal que estos viven. La muerte del parsi, cuyo cuerpo es arrastrado por Moby Dick, les prefigura su propio fin. En ese espacio de muerte los hombres están condenados. El mar se va convirtiendo en su cementerio, lugar de descanso final, o de muerte horrenda. La ballena no busca el encuentro de la misma manera en que lo hace Ahab. La locura es la de él, no la del leviatán, que circunda el mar y responde a los taques cuando estos se dirigen contra ella. Aún así, sigue afirmándose como el demonio ante estos, la portadora de muerte.
El cierre de la novela es el desarrollo de la batalla desigual entre marineros y ballena. $\mathrm{La}$ muerte deja de presentarse en un presagio y se convierte en la monstruosa realidad que Ahab y los suyos deben soportar. La caída de Ahab precipita el final. La muerte es inexorable, y el regreso a lo tétrico del su final se cierra con la idea de un mar siniestro la implícita referencia a la ballena inmortal:

Entonces volaron pájaros pequeños, chillando sobre el abismo aún abierto; una tétrica rompiente blanca golpeó contra sus bordes escarpados. Después todo se desplomó y el gran sudario del mar volvió a extenderse como desde hacía cinco mil años (Melville 2004: 412).

\section{Bibliografía}

Melville, Herman. 2004. Moby Dick. Grupo Editorial Tomo. México, D.F.

Miller, James E. 1977. A reader s guide to Herman Melville. Octagon Books. New York.

Sherril, Rowland A. 1981. El profético Melville. Experiencia, trascendencia y tragedia. Noema Editores. México, D.F. 